\title{
Evaluation of a transit-oriented development scenario in a medium-sized French city by simulation models
}

\author{
Olivier BONIN \\ Laboratoire Ville Mobilité Transport (LVMT) of UPEM, Ecole des Ponts Paritech \\ and IFSTTAR \\ olivier.bonin@ifsttar.fr \\ Lorenza TOMASONI \\ Laboratoire Ville Mobilité Transport (LVMT) of UPEM, Ecole des Ponts Paritech \\ and IFSTTAR \\ lorenza.tomasoni@enpc.fr
}

\begin{abstract}
TOD (transit oriented development) is a land planning approach that aims at developing harmoniously a transit network and the land it deserves both at the local and at the regional scale. It has been implemented successful in several large North and South American cities. Its transposition to Europe and small to medium cities is not straightforward, especially because European cities are much more dense than American ones, and transit is already well developed. However, TOD can also be considered as a means to coordinate existing land use and transport planning, and this is a major issue for all cities whatever their size or their density. Indeed, there is a co-production relationship between transport and land use, and the city development is systemic with many feedback loops between its subsystems. We show in this paper that a medium-sized city such as Besançon in France can benefit from a TOD approach for its development by designing scenarios and evaluating hem with a LUTI model.
\end{abstract}

Keywords: transit-oriented development, urban sprawl, urban modelling, modal share, urban development scenario

\section{Introduction}

The population living in urban areas steadily increases both in the US and in Europe, and cities grow accordingly. They often grow by spreading outside their limits and thus consuming rural areas. This process of urban sprawl is also referred to as suburbanisation. In the context of sustainable development, urban sprawl is considered to have several bad effects: suburban lifestyle is associated to and made possible by the usage of individual cars, and space consumption can impact biodiversity and hamper green and blue infrastructures whose interest has been highlighted by the Grenelle de l'environnement (round discussions around environmental issues that took place in France in 2007). Moreover, residential and commercial uses tend to be segregated in the fringes of the cities.

The classical political answer to this issue in France is to fight urban sprawl by discouraging car use and by increasing housing densities in the city centre. However, such a policy can have many drawbacks. Traffic congestion increases with the impediment of car use, with negative effects on air quality (even if greenhouse gazes emission can slightly decrease). Urban freight is a real issue in a dense city with many pedestrian ways. The competition for housing located in the centres has a direct impact on housing prices, preventing the less wealthy from settling downtown, which increases gentrification. More generally, a large proportion of the population declares to prefer individual houses and 
green amenities to apartments in city centres, so that the fight against urban sprawl is ill taken by many suburban inhabitants.

Transit Oriented Development (TOD) has emerged in the US as a possible means to fight urban sprawl. TOD is more than fighting land consumption; it aims at revitalising regions as well as promoting new lifestyles. Although the French context is quite different from the US one, TOD-like development has already been implemented with the Villes Nouvelles (new towns) strategy launched during the 70s. New towns are secondary poles planned and developed in the proximity of large cities, with a strong connexion by rapid transit to the city centres. Other European examples of TOD premises can be found in Sweeden, Germany, the Netherlands and Denmark.

Calthorpe (1994) distinguishes two scales of TOD: a regional (or interurban) one and a neighbourhood one. Thus TOD can be thought of as a multi-scale concept. At the local scale, TOD focuses on urban projects around some stations. The aim is to increase locally the density of inhabitants and services, so that stations become hearts of secondary centres. At the regional scale, TOD aims at implementing a hierarchy of centres around some well-connected key stations. Thus TOD manages to connect areas of different densities in the fringes of the city. Smaller public transport networks enable to extend the area of influence of the secondary centres in rural or less urbanized areas by enabling to reach the rapid transit network (Figure 1).



Figure1. Schematic illustration of the neighbourhood TOD and regional TOD concepts.

Both aspects of TOD are equally interesting for French cities. While public transport is probably much more developed in small and medium-sized cities than in the US (paragraph 2.2), this development is rarely sufficient to obtain correct densification around stations as well as a real hierarchy of places and functions in the city organized around public transport. Moreover, with the multiplication of the communautés de communes (intermunicipal authorities) the small and medium-sized cities, together with their neighbour municipalities are starting to adopt and implement land use and transport integrated urban strategies. 
We present in this paper a case study on a medium-sized French city (Besançon 250,000 with the surrounding municipalities) that evaluates the effect of TOD scenarios with the help of numerical models. We want to show from the one hand that the TOD concepts are relevant in a medium-size French city, whose context is different from the one of big US metropolises, and from the other hand that, despite the good level of the existing public transport network, an improvement of the network as well as an appropriate land use policy making use of the new patterns of accessibility are mandatory to achieve TOD both at the local and the regional scale. The simulations on Besançon simulation have been performed in the framework of the VILMODes project (funded by the French ministry for sustainable development). The VILMODes project also considers other options for urban developments such as imposing high densities in city centres [25, 27].

To be able to investigate the possible effects of neighbourhood TOD (urban development around stations) and regional TOD (extension of the public transport network to support the hierarchical development of city centres), we have designed and compared four scenarios. (1) The business as usual (BAU) scenario acts as a reference point for our simulations. (2) We add to this scenario a strategy of densification around stations, with the help of a fractal model (BAU-F) to evaluate the effect of TOD targeting the local scale, or (3) a strategy of reinforcement of the public transport network (BAU-I) to evaluate the effects of TOD targeting the regional (interurban) scale. Last (4), we combine the densification of stations the reinforcement of the public transport network to obtain the full TOD scenario.

By simulating and assessing the effects of implementing land-use or transport exclusive driven policies (BAU-F and BAU-I) compared to an integrated strategy (Full TOD), we try to address the following question: does coordination allow a real gain in terms of land savings/compactness and reduction of car use compared to the "exclusive" scenarios? Secondly, results from the evaluation of the TOD scenario will allow assessing the relevance of implementing a transit-oriented development in medium-sized French cities.

After a brief discussion on the TOD concept and its potential pertinence for European cities (section 2), we present the methodology used in this paper (section 3), the four scenarios that we have simulated and evaluated (section 4), and the results and conclusions we have obtained (section 5).

\section{Transit-oriented development: from U.S. to Europe}

\subsection{Definition of the concept}

As an urban project, TOD can be conceived in order to revitalise the inner city or to improve the potential for residential renewal in decayed urban areas and suburbs. TOD can also be a tool against gentrification, but its effects are not expected to be just in favour of weakly developed areas and low social classes. As the Mayor of Bogota said: "a developed country is not one where the poor drive cars, it's one where the rich use public transportation". To affect people modal choice, no matter their social rank, and to enable a substantial modal shift from the individual car to transit are the two main targets of TOD that we consider here. To reach this goal, a project of transit oriented development acts not only by means of transport policies, but also through land-use strategies. Competitiveness and attractiveness must be ensured from the transit point of view at a metropolitan, regional and local scale, but also from the liveability viewpoint at all scales. 
Sometimes the balance is not easy to achieve especially if decisions are made at different levels and by different authorities [1]. Governance is a challenge and strong political personalities are often behind successful TOD stories.

Cervero identifies different ways for implementing TOD. According to the urban resilience level of a city [1], defined as the capability of an urban system to adapt to changes, and to the adopted urban development strategy, he distinguishes four types of implementation: the adaptive city (transit oriented development), the adaptive transit (oriented development transit), the hybrids (a good coordination between transit an urban development) and strong core cities (transit as the motor of downtown revitalisation). Although all TOD projects aim at harmonising land-use and transport strategies, it must be taken into account that decision-makers act the most of time on existing urban system, each one with its own peculiarities and weaknesses [5]. That is the reason why, sometimes, oriented development transit models are as well consistent with (and not opposite to) transit oriented development goals. That is not the case for adjacent oriented development (or transit related development) that means a coherent, but not coordinated, urban and transportation development.

Finally, Bernick and Cervero [15] emphasize the role of the "three Ds" (density, diversity, and design) in the success of TOD at the local level. Although proper built form is a necessary element that alone is not sufficient for achieving all the benefits of TOD at a larger scale.

\subsection{Urban and public transport development in US and Europe}

We have previously said that public transport networks are not equally developed in US and Europe where almost all big and medium cities hold a transit system. As a consequence, the increase of travel distances due to urban sprawl has more stressed the use of car in US than in Europe. Such differences have historical and cultural causes.

In the United-States as well as in Europe urbanisation has moved from a Development Oriented Transit (DOT) [29] in the early 20th century, to a Transit Oriented Development (TOD) driving today urban development strategies.

As known, from a planning point of view, the years from 1950 to 1980 have been characterised by an Automobile Oriented Development (AOD) in the US as well as in Europe. In 1990 the average car share of urban passenger transport was over $84 \%$ in the US, while in Western Europe it was at $43 \%$. In the same year public transportation rates were averagely at 3 and $13,5 \%$. Reasons for such a difference are due, from the one hand, to a higher private vehicle ownership rate in the US than in Europe and, from the other hand, to a weak and poor land-use regulation in the US, which favoured a laisser-faire culture as for urban development. In US the individual interest has for many years prevailed on the community one while in Europe the higher compactness of cities encourages the decisional level to work in favour of a common interest and, in this aim, to the development of public transportation systems, at least in central urban areas. Today, the car ownership rate remains significantly higher in the US (812 vehicles per 1000 population) than in Europe (498 vehicles per 1000 population).

However, where does the urban sprawl come from? Data on the spatial distribution of the population within cities show that urbanisation is accompanied by a rapid expansion of urban space at the fringe of cities. Thus, in OECD countries, population rapidly grew in suburban areas and built-up areas increased threefold between 1950 and 2000. A study publicized by the Ecological Society of America showed that, assuming a three levels scale of housing density (urban, exurban and rural), in 1950, the US had less than $1 \%$ of 
land at urban density and nearly 5\% at exurban density. Since 1980 we have assisted to a rebound with widespread population and migration gain in non-metropolitan counties [1]. Location choice was no more based on economic factors, but on accessibility to amenities. Such an expansion of non-metropolitan areas reflects the effect of decreasing household size and settlement densities [2]. In 2000 values of urban and exurban density increased until reaching respectively $2 \%$ and $25 \%$. That means that urbanisation, since 1950, has occurred almost exclusively in exurban than urban areas in US. According to data from OECD (2006) a large number of U.S. cities make register similar values of urban and total land (urban+exurban) density, while in Europe exurban density is averagely four time less than the urban one. However, it is a fact that also Europe is affected by urban sprawl, but density indicators are definitely not comparable between European and US cities. Metropolisation [14] and suburbanisation are the dynamics most commonly used in Europe to explain the enlargement of urban areas.

Some of the metropolises taken into account into the OECD study are considered as successful example of TOD implementation. That is the case of the cities of Atlanta, Dallas, San Diego [15], Stockholm, Copenhagen, Munich, Portland and Saint Louis [19]. The table below shows that those cities have very different profiles in terms of population concentration and density. The spatial aspect has always to be put into perspective when studying and explaining urban functioning (mobility).

Table 1. TOD cities in the OECD study.

\begin{tabular}{|l|l|l|r|}
\hline Country & City & Dtl & \multicolumn{1}{l|}{ Dul } \\
\hline Denmark & Copenagen & 490,4 & 1961,9 \\
\hline Germany & Munich & 417,1 & 2706 \\
\hline Sweden & Stockholm & 473,3 & 1899,6 \\
\hline United States & Atlanta & 489,9 & 899,1 \\
\hline United States & Dallas & 272,8 & 1091,1 \\
\hline United States & Portland & 169,5 & 1049,1 \\
\hline United States & Saint Louis & 189,6 & 794,7 \\
\hline United States & San Diego & 620,5 & 1494,9 \\
\hline
\end{tabular}

Considering public transport, today experts and decision makers are quite optimistic about the effects of effective policies in favour of public transport. Considering 17 of the biggest (more than 1 million inhabitants) US cities public, transportation share reaches an average rate of 16\% (Census American Community Survey, 2009). Such an average rate falls to $11,5 \%$ if we add medium cities values for public transportation.

The same trends can be observed in Europe, where rates are however significantly higher than is US. In fact, the average public transportation share is of $32 \%$ (Urban Audit, 2009; EMTA, 2009) if we considered the biggest cities, and $27 \%$ if we extend this calculation to a certain number of medium cities. But, what is more interesting to observe in Europe is the gap of modal splits at the metropolitan rather than urban scale. Average public transportation rate, measured at metropolitan scale, is of $19.6 \%$ while it is of $29.4 \%$ if considered data from the only urban areas. That shows, from the one hand, that European cities strongly acted in favour of public transportation in densest areas making cities more compact not only from the spatial, but also from the functioning viewpoint. From the other hand, such data highlight a difference in the performance of public transport in big rather than medium cities, but also in central rather than peripheral areas. 
In the US context where the individual car is definitely the predominant transport mode, where daily trip distances are importantly larger than in Europe, where the decline in public transit's share of metropolitan travel has been more precipitous that nowhere else and, finally, where urban areas extension is extremely high, TOD based on regional strategy and heavy transport modes [18] seems the suitable strategy for this kind of urban development pattern. In fact, TOD in the US is often seen as a project implemented in regional metropolises and based on mass-transport systems like light-rail, BRT, express buses, streetcars, commuter trains and high-speed rail system. What we try to show in this article is also that an urban and interurban TOD is possible and that it is more pertinent to European and in particular to French cities.

Whether transport habits, density values and urban forms are not fully consistent in Europe and US, nonetheless we can say that they shared the same concerns as for urban development. In fact, at current rate, built-up areas, in Europe as in US, are expected to increase at least twice faster than total population [23] in the coming years. Thus, if landuse and transport policies are not coordinated, the risk is to fall back into an oriented development transit instead of transit oriented development logic.

Many practitioners and scientists defend the idea that "densest is better" [16, 17, 25]. But is the compact city the only possible answer against urban sprawl? Is the increasing of density the only way to go [22]? Is TOD adapted to medium and small cities in Europe? One of the assumptions we do in this paper is that compactness must address not only density, but also spatial repartition of functions (land-use) as well their usage (mobility and people behaviours). Thus we consider that both the dense city model and the TOD model can achieve some kind of compactness (in the sense of avoiding large voids and keeping the different parts of the city connected) [27].

\subsection{The three dimensions of TOD}

The aim of this article is not to reconsider the US TOD model, but to defend the idea that the principles behind TOD can be adapted to European urban areas and that urbanisation without "deruralisation" of minor centres is achievable.

Everybody agrees on TOD as a project for harmonising land-use and public transport. Taking into account US and European urban models and TOD main features and objectives, we identify three dimensions 1 of TOD in which to promote coordinated actions.

1. Land-use and planning. The focus is on urban sprawl and densities levels. Indeed, scales of reference are not comparable between US and European cities. A sprawled city in Europe could be considered to be compact in the US. Density values should be defined locally following a hierarchic logic (density gradient) according to urban functioning and residents' expected lifestyle. Furthermore, European urban areas are less extended than US ones, and urban sprawl affects big as well as medium cities. We think that TOD is not exclusively for metropolises, but is accessible to all cities with no a priori limitation as for their dimension. Density distribution and land occupation remain meaningful

\footnotetext{
$1 \mathrm{We}$ assume that we cannot act on the political/institutional dimension neither on the financial one. Models applied in the field of the VILMODes project do not allowed simulating stakeholders and decision-makers and the cost of measures is not taken into account. They are developed to be decision support systems (DSS) and scenarios are not evaluated taking into account the cost of measures but their benefits (social, economical and environmental). Although we are aware that in the real decision-making process those two dimensions are crucial, from a research point of view we find it acceptable not to base our scenarios on political and financial conditions but only on sustainable development targets.
} 
indicators for the identification of sprawling areas. However we sustained that compactness is not an urban form exclusive of monocentric and dense areas. Polycentric forms are also suitable for building the compact city as compactness is not just about concentring, but distributing densities in order to favour transit accessibility and at the same time to satisfy people preferences as for location choice.

2. Transportation. The quality, performance and supply of public transport must be improved in order to attract car users towards transit. Accessibility to daily activities by transit should be reinforced at first. Considering French cities priorities are (1) to reinforce transit supply in peripheral and rural areas; (2) to improve the quality and performance of transit in central area; (3) to improve intermodality between transit modes (mass and non-mass transit systems) but also for transfer (park\&ride and bike\&ride systems especially in peripheral and rural areas). The aim is to improve the competitiveness of public transport face to the flexibility of the automobile.

3. Behaviours. Whether land-use and transportation are incentives in the hands of public decisional levels to endorse transit-oriented development, changing in individual mobility behaviour is a target. The objective of TOD is double from this point of view. From the one hand TOD wishes to influence people modal choice by making public transportation more attractive and urban daily functions more accessible by transit. From the other hand, TOD aims at making "accessibility to transit" a most important criterion of location choice for households and firms by fostering new urban development in transit-accessible areas.

TOD should not be perceived as an overinfrastructuring of lands, as it was intended during the Automobile Oriented Development years, but it is a mean to adapt cities to the imperatives of sustainable development and to conceive urban forms that can still expand in a sustainable manner.

Our case study is a French city. We propose to consider TOD in France more as an inflexion of existing policies rather than a completely new approach. Some attempts towards land-use and transport coordination have already be implemented in France with moderately satisfying results. Returns on experiment show that coordination in France would need to be improved especially from the governance and decision-making viewpoints. However we seek in our research project to find sustainable forms of urban development without taking caring of "political" constraints. Our criteria for evaluation are the benefits for people and for the environment. Effective planning instruments allowing decision-makers to apply TOD already exist. We study them briefly here to be able to take them into account in the way we build our scenarios.

\subsection{Co-evolution of transportation and land-use management in France. Opportunity for coordination and TOD}

The question of the coordination of transport and urban planning policies is quite intricate in the French context, mainly because these policies are designed and implemented at different territorial scales. Transportation networks are planned at different levels according to their spatial extent and capacity. Road and railway networks are planned at the national scale, whereas local transit systems are implemented at the city scale. 
Urban development is generally planned at the city scale. Mayors are in charge of land use planning, via the permis de construire (planning permissions) and the plan local d'urbanisme (land use master plan) that defines the zones that can be urbanised as well as restrictions on building density.

The regional scale, in-between the national and the city scale is now the scale where transport and urban planning can meet. Indeed, with the decentralisation, the management of road and railway networks has been transferred to the regional scale when these networks are of regional interest. Moreover, many small cities gather in intercity coordination structures closer to the regional scale than to the local scale.

This is why we consider that the most pertinent scale for developing coordinated landuse and transport scenarios in this study is the CAGB (Communauté d'Agglomération du Grand Besançon - intermunicipal authority for the greater Besançon) that designates the city of Besançon together with its surrounding municipalities.

However, even if there is now in France a better context for the coordination of transport and urban development policies, many issues need to be addressed. The hardest one is systemic: it is clear that transportation and land-use are two subsystems so intricate that it is impossible to explain the evolution of urban systems partly as the result of the growth of multimodal transport systems, as well as it is impossible to explain the development of the transport system as a process purely driven by urban expansion. It is a co-evolution process that must be handled globally to overcome the chicken and egg problem. Thus, an effective TOD cannot rely on standard recipes but must take into account the history and the dynamics of the territory on which it is implemented.

There is another reason that makes difficult the coordination of urban systems and multimodal transport systems. These systems are under the stress of an ever growing urban population and a context of globalisation, so that the extent of these systems is always evolving. Urban planners and transport planners must at the same time find solutions to congestion problems and economic inefficiency and be able to forecast the evolution of their territory in a globalised system and under great financial constraints.

Urban systems are especially constrained by two physical considerations. First the available free space for new housings on a territory is not infinite, especially given the historical development of cities with many places that can barely evolved because of historical and architectural considerations, as it is the case in many city centres. This is especially true for Besançon, with a small historical centre and many natural constraints due to the presence of mountains and many natural areas.

Secondly, centrality always emerges because of the agglomeration of employment and activities, so that it is necessary for all the inhabitant of an urban system to be able to reach at least one centre in acceptable time. Thus the distance between centres and the perimeter of the agglomeration cannot grow to a point where transit times are excessive. For a growing city, there is clearly a trade-off between increasing the housing densities and increasing its spatial extent to the price of higher commuting times and energy consumptions. This last point is now considered as a major issue in the context of energy rarefaction and environmental nuisances associated to individual cars.

Therefore, we propose four scenarios that support the development of a compact (i. e. with not too many voids) but open city that can grow outside their perimeter A compact and open city must have a backbone along which are located several centres, possibly of different sizes: employment centres, historical centres, activity centres, etc. This backbone must be a transit network, enabling mobility of inhabitants along this backbone. To be 
efficient, centres must emerge, and to meet the expectations of today's periurban inhabitants, this backbone must also reach areas of lesser densities.

\section{Methodology}

We present now the construction and simulation of urban development scenarios. We want to specify our scenarios only with the tools that urban planners at the local and regional scale might use, so that a scenario could serve as a basis for actual implementation. As these scenarios are simulated and evaluated by some models, we also present these models in this section, and discuss the way we use them.

\subsection{Design of a scenario}

We consider that an urban development scenario is made, from the one hand, of assumptions about the possible evolution of the macroeconomic and demographic local context, and from the other hand, of public policies and interventions. To be acceptable, a scenario must put the city on the path of sustainable development without constraining excessively the residents' aspirations and lifestyles.

All scenarios built in the field of the VILMODes project are based on the same assumptions with respect to the macroeconomic context.

We add some additional constraints on our scenarios given the tools that we use to assess them. To shed some light on the possible effects of public policies, we must make sure that the way we construct our scenarios and the models we use to assess them are not overconstrained to produce the results we seek to obtain.

In this study, a scenario is defined and evaluated in four steps:

- definition of a land-use master plan, i.e. where and what kind of urbanisation is allowed;

- definition of transport supply: networks, capacities, stations and frequencies (for transit)

- simulation of property developers according to the land-use master plan and accessibility to amenities (employment, shops, services, public transport, green spaces)

- simulation of daily mobility and residential mobility (sometimes referred to as mobilities in the present arcticle)

The first step can be performed by hand, or with the help of a specific model if we want to satisfy some constraints. In case of the conception of the TOD scenario, we want to have different densities and patterns of development for the urban TOD centers and the neighborhood TOD centers. Therefore, we adopt a multifractal approach [34] that enables to combine a hierarchy of spatial urban functions with the preservation of connected green lanes and a diversity of urban densities at different scales. In case of the reference scenario (business as usual), we detect the frontiers of the actual urbanized area to define the limit between urban and rural areas. In both cases natural and protected areas are preserved from urbanization.

Taking into account that accessibility to diverse amenities is crucial to understand the location choice of property in European cities, we use the MUPCity [11] model to evaluate for each elementary cell of the land use master plan its accessibility to employment, shop and services (with a hierarchy of services as regards the frequency at 
which they are used: daily, weekly and monthly), to public transport stations, and to the green spaces (parks, forests, lanes). The most accessible cells (best MUPCity evaluation) are developed first. As can be observed in the real world, public developers can overcome the land use master plan if there is no more free space left.

The simulation of daily and residential mobility is performed with the help of Mobisim [13], a LUTI (Land-Use Transport Interaction) model already calibrated on the Besançon region. The simulation of daily mobility takes into account mobility chains rather than conventional round-trips, with four possible modes: car, transit, walk and bike. The simulation of residential mobility relies on a new model under development [26].

The macroeconomic and demographic local context has naturally a great impact on simulations. In all cases, we use reference data and forecasts (INSEE for population, and EIA for energy price). We choose a moderate increase as regards gasoline price $(+60 \%$ between 2010 and 2030) and a linear projection for demographic trends.

\subsection{Simulation models}

One of the originalities of our approach is to make use of space based models as well as individual based models to design and evaluate our scenarios. Naturally, we are very concerned by making sure that there are enough degrees of freedom in the way we design and evaluate our scenarios, so that the effects that we show are real simulated effects and not forced effects.

The specification of the transport networks does not require the use of any model, beside the GIS definition of lines and stops.

The definition of the land use master plan could be done by hand. We choose to rely on simulation models to ensure that our master plan is not unrealistic, and bear some "good" properties that we want to impose. To define a land use master plan consistent with a neighborhood TOD approach as well as with other constraints (namely, variety of housing densities, accessibility to nature and preservation of green and blue infrastructures), with use Fractalopolis. The application of Fractalopolis to TOD has been presented in [30]. Fractalopolis helps to design interactively multi-fractal patterns of housing development by computing areas where densities are suboptimal and areas where densities are already too high, so that we obtain a hierarchy of centers and of densities at different scales. We have used Fractalopolis to determine the densification around stations that we consider to be optimal, both for collective and for individual housings.

MUPCity, a space-based model that computes for each cell of a regular grid the generalized accessibility to several amenities, performs the simulation of property development. Indeed, property developers generally try to develop first the areas that have the highest potential in terms of accessibility. Naturally, this property development is guided by the land use master plan defined at the previous step.

Finally, Mobisim is the LUTI model that is used to simulate daily mobility as well as residential mobility. Mobisim is an agent based model that create a synthetic population for the whole city, and simulates their behaviors. Mobisim enables us to assess the efficiency of a scenario according to several criteria.

\subsection{Four scenarios}

As we have seen, TOD, if reduced to a mere coordination of transportation and land use policy, seems to be a common practice in Europe. To understand better the co- 
construction of urban areas and transportation networks we have design four scenarios that are archetypes of possible interpretations of the TOD concept (Table 2):

1. BAU (business as usual) is our reference scenario, with no modification of the existing urban master plan, and no development of the transit network except for the tramway to be opened in 2015

2. BAU-I (interurban), the same scenario with an enhanced transit network to reinforce the interurban level

3. BAU-F (fractal) the fractal master plan developed with Fractalopolis that enables a densification around existing stations and the emergence of new urban centers, with the same network as the BAU

4. TOD: the complete TOD scenario that combines the fractal master plan and the new network.

As simulations will be probably far from reality, given the imperfect calibration of the models and the difficulty to predict the evolution of the economic and demographic context, we use the BAU model as a reference point for our comparisons.

Table 2. The four simulated scenarios.

\begin{tabular}{|l|l|l|l|l|l|}
\hline Scénarios & \multicolumn{2}{|l|}{ Transit } & \multicolumn{2}{l|}{ Urban development } & Hypothesis \\
\cline { 2 - 5 } & Urbain & Interurbain & Non-fractal & Fractal & \\
\hline BAU & ++ & + & + & & $\begin{array}{l}\text { Strengthening of the existing } \\
\text { main centre(s) } \\
\text { Sprawling urban development } \\
\text { Increasing of car use in the } \\
\text { suburban areas }\end{array}$ \\
\hline BAU-I & ++ & ++ & + & & $\begin{array}{l}\text { Sprawling urban development } \\
\text { but emergence of new centres } \\
\text { around suburban stations } \\
\text { thanks to an improved } \\
\text { accessibility }\end{array}$ \\
\hline BAU-F & ++ & + & $\begin{array}{l}\text { Increasing of public transport } \\
\text { use in suburban area }\end{array}$ \\
& & & & & $\begin{array}{l}\text { Compact urban development } \\
\text { and clear emergence of } \\
\text { secondary centres } \\
\text { No substantial changes of the } \\
\text { transport modal share }\end{array}$ \\
\hline TOD & ++ & ++ & $\begin{array}{l}\text { Emergence of secondary } \\
\text { centres around new stations } \\
\text { Strengthening of the } \\
\text { interaction between suburban } \\
\text { area and the main centre } \\
\text { Increasing of public transport }\end{array}$ \\
\hline
\end{tabular}




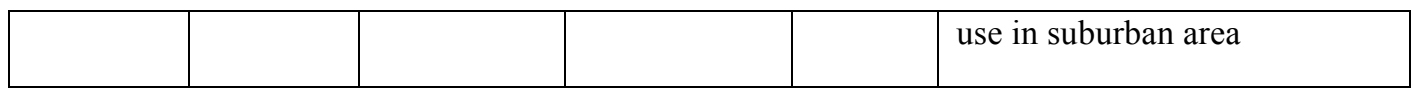

BAU-I and BAU-F are two different directions for public intervention. In the BAU-I scenario, most of the effort is made on public transport development, while urban development remains with the same constraints as today (i.e. leading to urban sprawl). With this scenario, we try to investigate if public transport development is sufficient to drive urban development towards densification around the stations. In the BAU-F scenario, we consider that the development of the public transport network is sufficient, but that urban planning policy must encourage property developer to build around the stations and to limit urban sprawl. The TOD scenario is of course the combination of both public incentives (Figure 2).

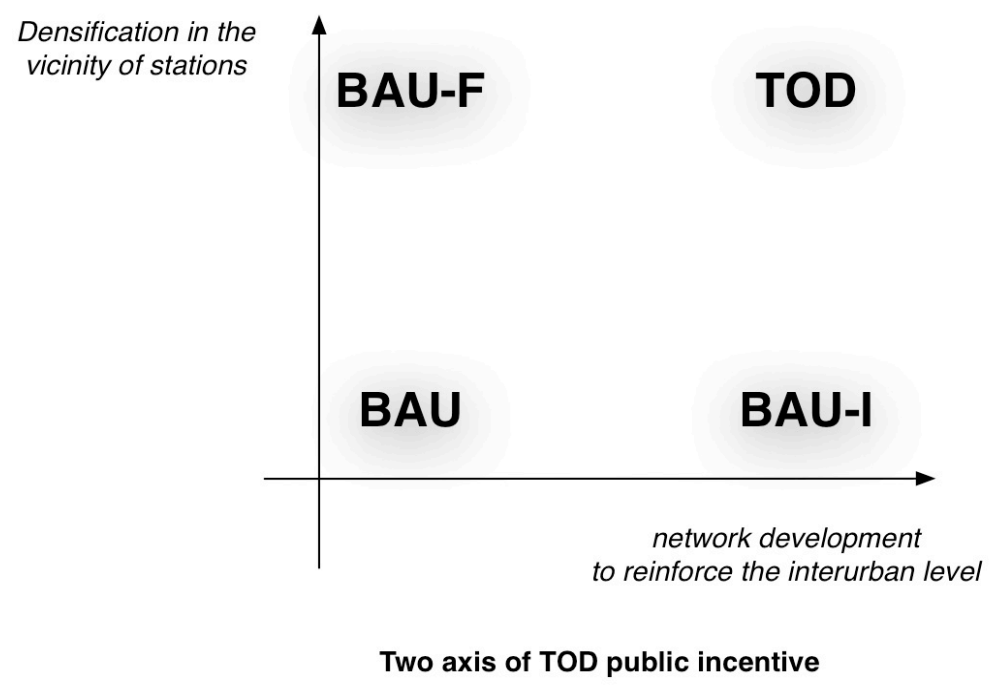

Figure 2. Classification of our scenarios in terms of public incentive.

The question is far from being simple in our case study because Besançon is somehow on the path to TOD, so our question could be reformulated as: "what is the next step towards TOD?" and "is coordination of transport and land use policy really a requirement for TOD or is one of these policies strong enough to drive the other one?"

\section{Case-study: scenarios for the city of Besancon (France)}

\subsection{Besançon}

Besançon is a medium city of 117.080 inhabitants situated in the East of France (Franche-Comté Region). It is located in an area rich of natural sites and landscapes.

Besançon was established in correspondence of a large meanders of the Doubs surrounded by seven hills. The old city is densely built following a grid-pattern and it is where urbanisation almost exclusively occurred until the industrial revolution. The city expanded and today neighbourhoods at the urban border are also densely inhabited. Those neighbourhoods absorb an important part of the demographic growth. The urban sprawl main direction if from southwest to northeast. This is partly due to the southern hills that prevent urbanisation towards the south (Figure 3).

The city of Besançon represents an important part on the whole Community of Agglomeration of Greater Besançon (CAGB) where 179.000 inhabitants live. It counts for $66 \%$ as regards population, $79 \%$ as for employment (i.e. 65.000) and concentrates 
main activities, infrastructures and other equipment generating important traffic flows (shops, schools and university, hospital). Except for Besançon, the other municipalities of the CAGB hold a population varying between 1.000 and 2.000 inhabitants. Urban functioning at the community level is therefore essentially monocentric.

In terms of public transportation an efficient bus network disserves the CAGB. At present Besançon is a great work in progress because of the choice of equipped the city with a Light Rail Transit. The new tramway will ensure the connection between the Jean Minoz regional hospital centre in the southeast and the Chalezeule mall in the northeast. The new line will disserve also the central area and the old city.

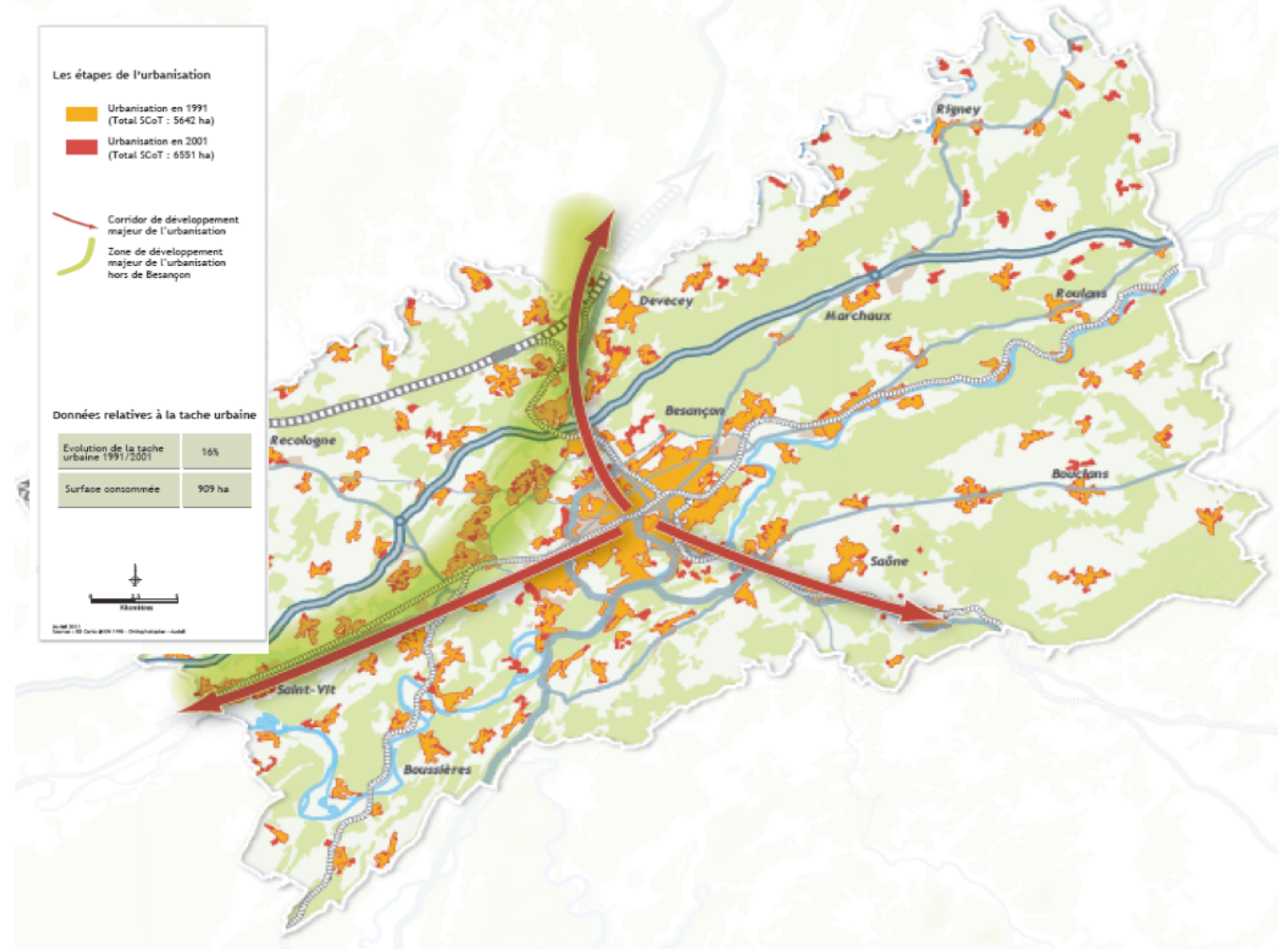

Figure 3. Main processes of urbanisation in Besançon (Source: SCOT CAGB).

Besançon is a much smaller city than those the literature usually associates to the concept of TOD. The change of scale when jumping from the US to the European context is however quite evident if we consider two of the most common example of European TOD, the city of Stuttgart and the city of Copenhagen. However, such a difference in scale and dimension did not protect the city of Besançon from urban sprawl. Households have been leaving central area looking for rural lifestyle and country landscapes. The LRT project shows that as many European monocentric metropolises also the city of Besançon promotes an important transport project in favour of urban dense areas. This project is in the aim of supporting spatial compactness with a compact functioning and effective transit system. As for many compact monocentric cities, low-dense suburbs are not directly concerned by such a project. Those elements justify the development of a TOD project to reinforce the connection between central areas and surrounding villages of the CAGB.

The CAGB holds an important potential in terms of rail transport, as the use of the existing infrastructure is not optimised at the local level. Therefore TOD project 
we propose is in the aim of slowing down urban sprawl; allowing compact urbanisation of surrounding lands without threatening open spaces and green areas; and encouraging the use of transit by improving supply and accessibility to the network at different scale.

\subsection{Implementation of the four scenarios}

The four scenarios are simulated on the $2010-2030$ period. We begin our simulation in 2010 for two reasons. The first one is that 2009 is the last year for which we have statistical data used to generate the synthetic population in the disaggregated LUTI model. The second one is that 2015 will show a significant change in the transit supply in Besançon with the opening of a new tramway line. Thus, we observe in all scenarios the effects of the tramway in 2015.

The BAU-I and the TOD scenario simulate an updated transit network (besides the tramway) designed according the objective of supporting a regional TOD development. Thus timetables are modified [35] in order to guarantee a train every 30 minutes and some new stations are added on the network to deserve existing premises of secondary poles. Thus the network in these scenarios has better extend and better frequencies.

The BAU-F and the TOD scenario use an urbanization pattern as land use master plan that we have defined with the help of Fractalopolis (Figure 4).

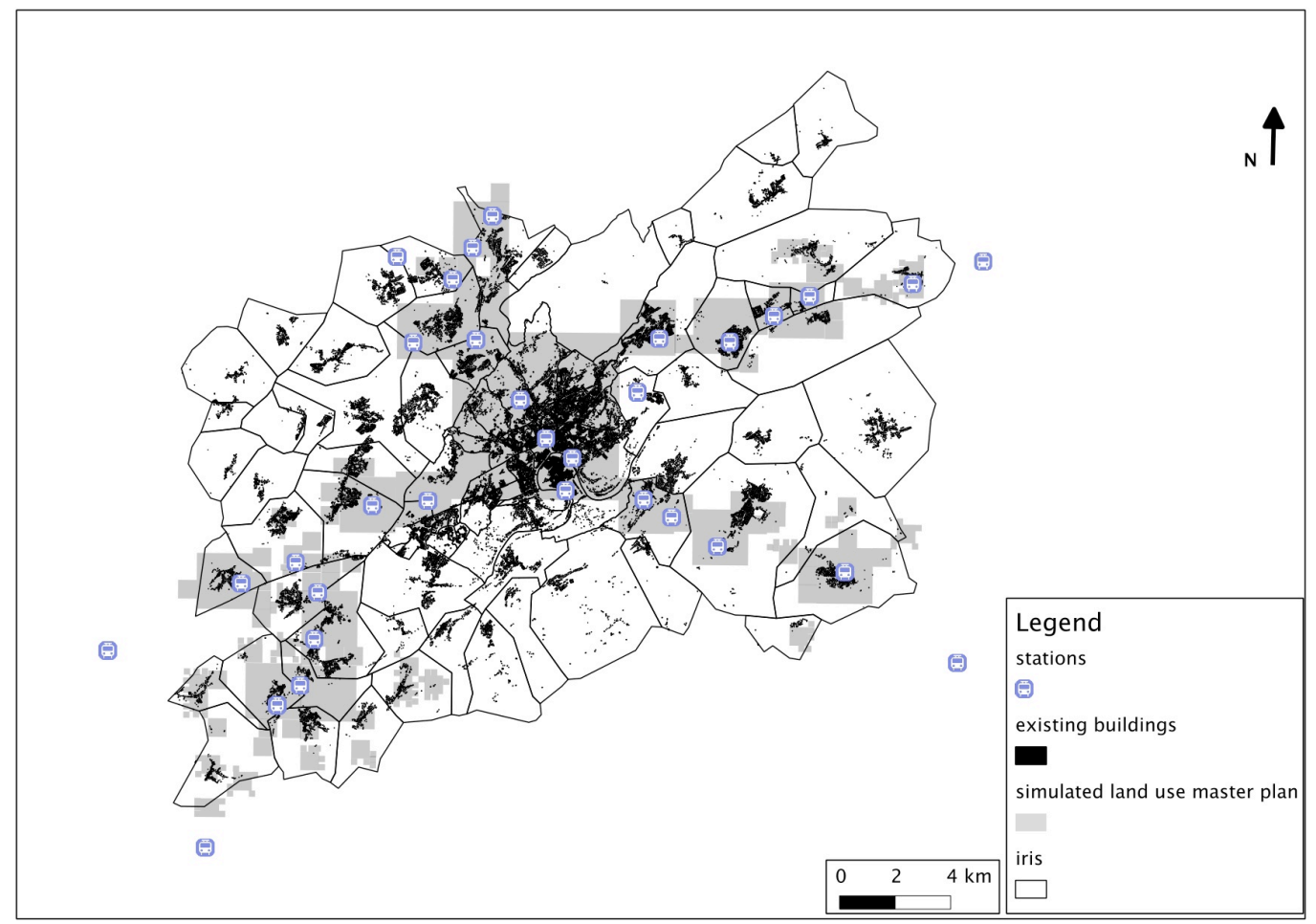

Figure 4. Land use master plan for the BAU-F and the TOD scenarios (computed with Fractalopolis): the grey squares are open to urbanisation (with the exception of the city centre), with constraints on the types and densities of buildings that may be built.

Note that the largest square centred on Besançon is totally closed to urbanisation in the BAU-F and the TOD scenario. Indeed, the density of the city centre is already quite high, and there is disequilibrium between the city centre and the secondary centre, so that we choose to try to equilibrate the situation with our land use policy. 


\subsection{Results}

The mobisim model records extensive data on the simulations, so that we can compute afterwards many indicators. As one of the key imperatives of sustainable development is to reduce car use and hence energy consumption, greenhouse gases and pollutants, we look first at modal shares and distances.

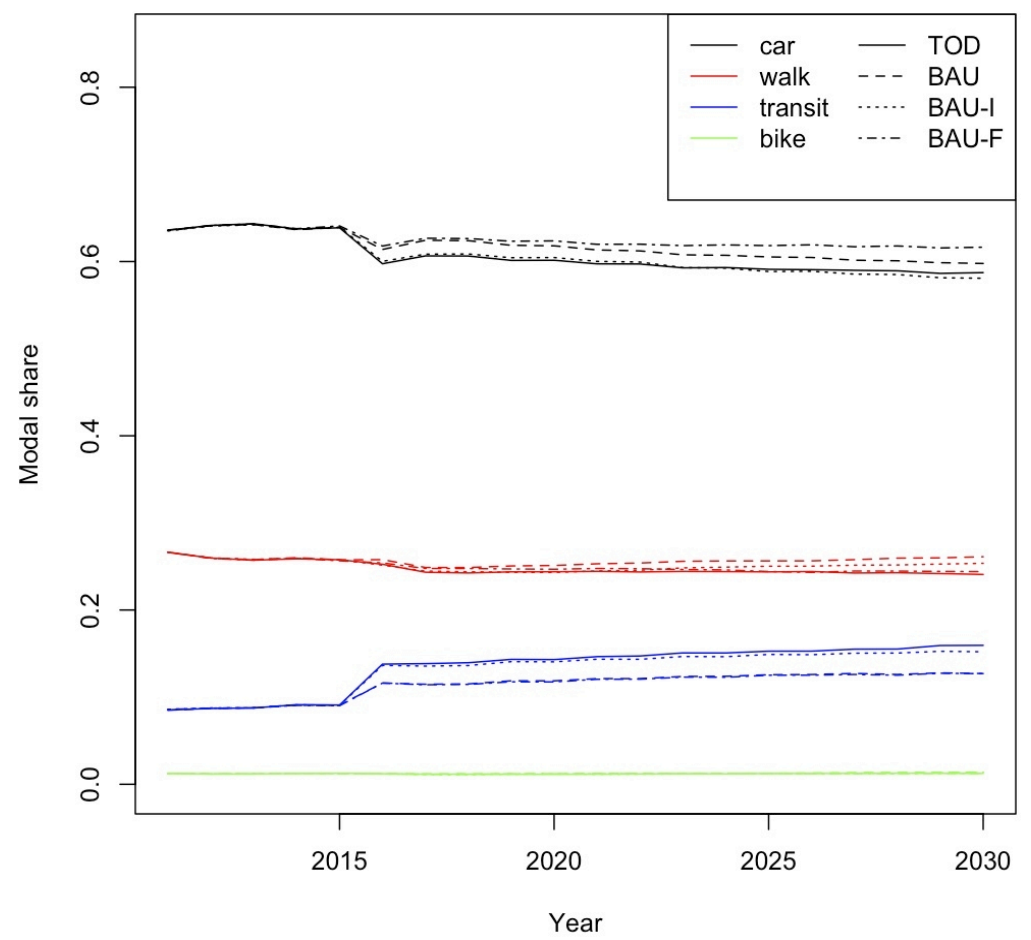

Figure 5. Modal shares for car, walk, transit and bike in the four scenarios.

If we look at the car modal share (Figure 5, in black), we observe first that the main effect is the opening of the tramway line in 2015. This effect is visible for the four scenarios. However, the small modifications of the transit supply in the BAU-I and TOD scenarios have a significant effect: both scenarios make the car modal share decrease of $1 \%$ in 2030. More surprisingly, a land use policy of densification around stations implemented on the existing transit network (BAU-F) leads to a slight increase of the car modal share in 2030 with respect to the one in 2015, highlighting that the existing transit supply is not sufficient to satisfy the resulting demand. The coordination of both policies (TOD) yields the same results as the effect of the network alone (BAU-I).

The spatial repartition of transit modal share (Figure 6) validates our expectations showing a good spatial extension of transit use thanks to the improved timetable and the new stops. Thus transit is not restricted to the inhabitants of the city centre but accessible and used by a large part of the territory, diminishing thus the requirement for car ownership. 

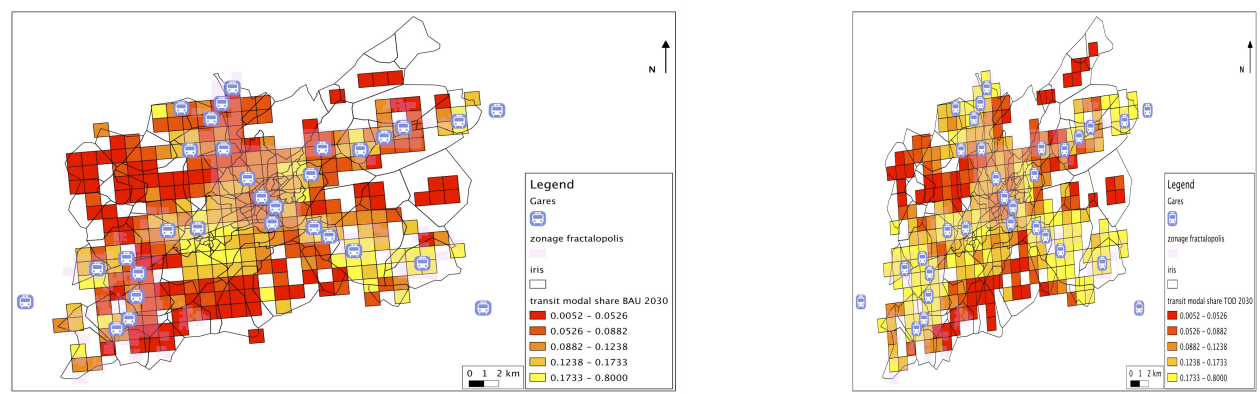

Figure 6. Transit modal shares in 2030 for the BAU scenario (left) and the TOD scenario (right).

However, modal shares are not sufficient to evaluate the performance of our scenarios as far as car use is concerned. Figure 7 shows the average distances of trips performed by transit. The TOD scenario shows an increase in travelled distances (considering all reasons for journey), highlighting the capacity of this scenario to use efficiently the transit network (i.e. for long distances) as well as connecting the secondary city centres at the regional scale (Figure 7, right). These larger distances are covered at the expense of a moderate increase in travel times (around 5 minutes, Figure 7, left).
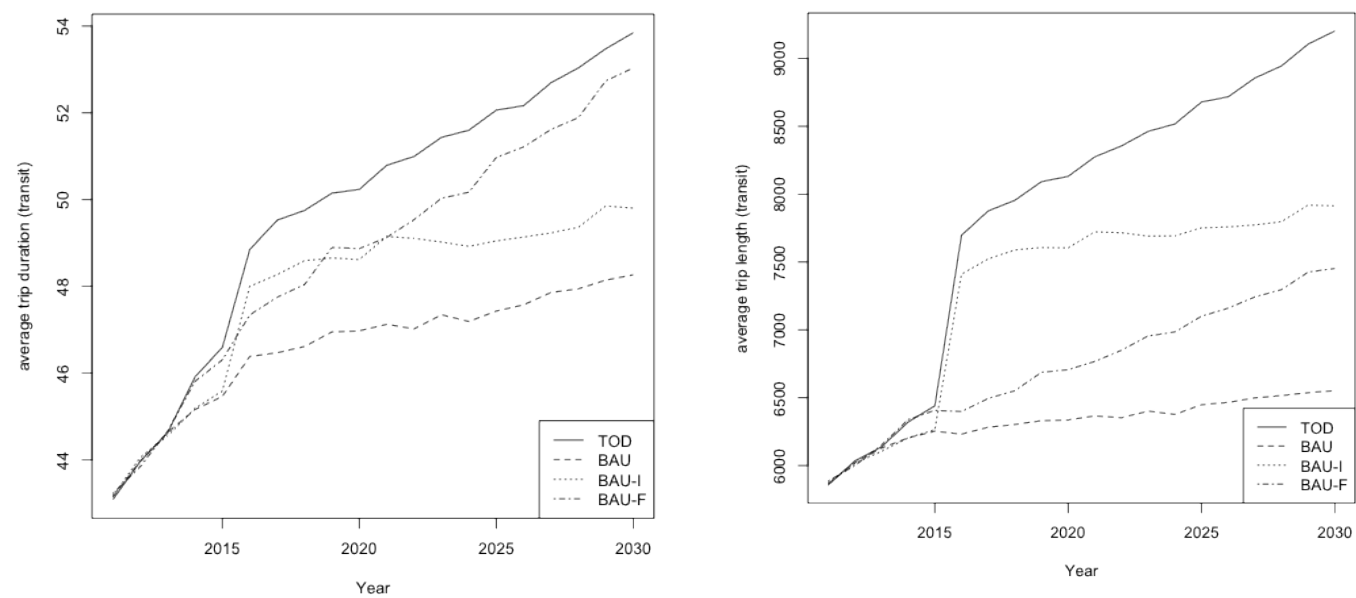

Figure 7. Evolution of average trip duration (left) and average trip length for transit.

These results are consistent with the urbanisation patterns that we obtain in our scenarios (i.e. Figures 8 and 9). 


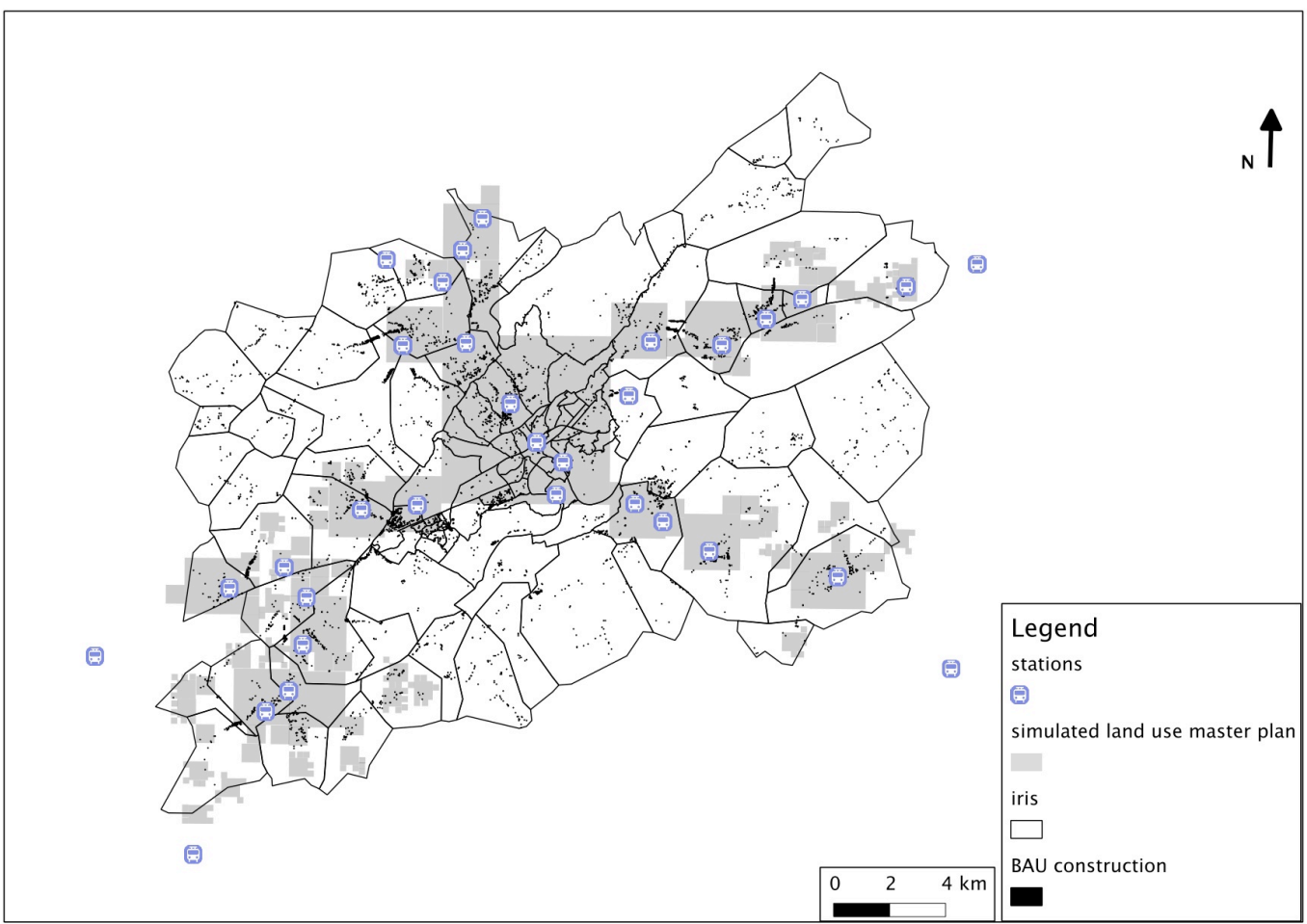

Figure 8: Residential development (construction) in the BAU scenario up to 2030

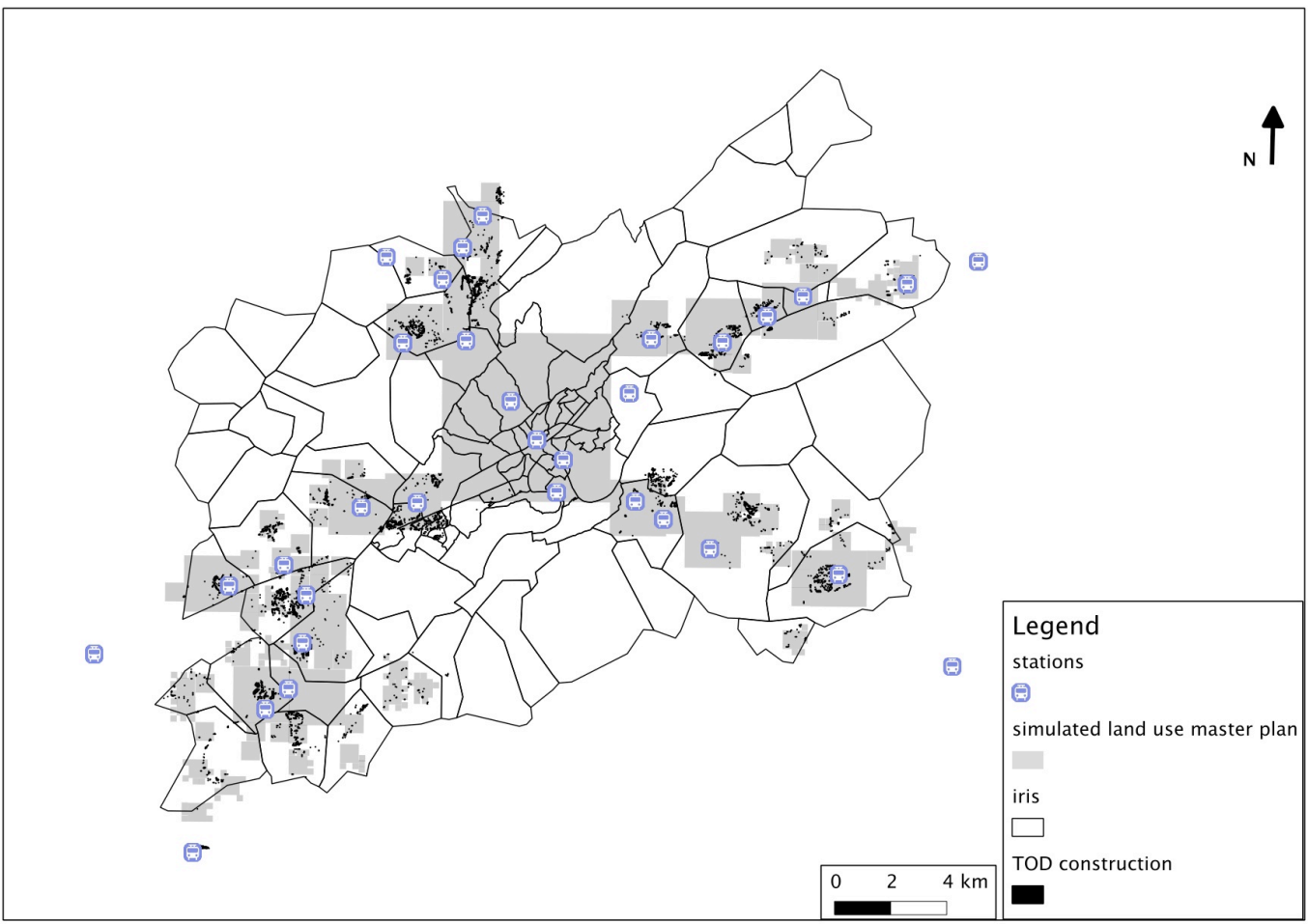

Figure 9: Residential development (construction) in the TOD scenario up to 2030

The BAU-I scenario leads to an extension of the urban sprawl, as no constraining land use master plan prevents property developers to consume rural space (Figure 8). We see however concentrations of new housings in areas where many amenities are accessible. That results from the accessibility approach that we took as an assumption in our research 
and that addresses land use development in our four scenarios (paragraph 3.1). On the contrary, the TOD scenario (Figure 9) leads to urbanisation mostly following the recommendations of the simulated land use master plan (gray squares) based on a fractal densification approach. Thus we show that the development of the transit network alone is not sufficient to drive a TOD-like urbanisation. The TOD urbanisation has many advantages over the BAU-I one: green and blue infrastructures are preserved, there is a mix of high and low density areas at all scales that allows satisfying people's aspiration toward individual houses and natures without consuming further rural areas. Finally, the emergence of secondary centres makes possible the development of new services and new shops in these areas.

Mobisim allows also evaluating scenarios from the social viewpoint. Classes of income characterize the synthetic population in Mobisim. We observe from the state of the art in 2011 that high-income areas (Figure 10, in yellow): more than $60 \%$ of high income households in a cell) are located mainly in the fringes of the city and low-income areas in the centre, resembling the American model. In the TOD scenario (Figure 11) the lowincome central area is somewhat reduced and the high-income areas less concentrated and slightly nearer the centre, representing a step forward a weaker socio-spatial segregation.

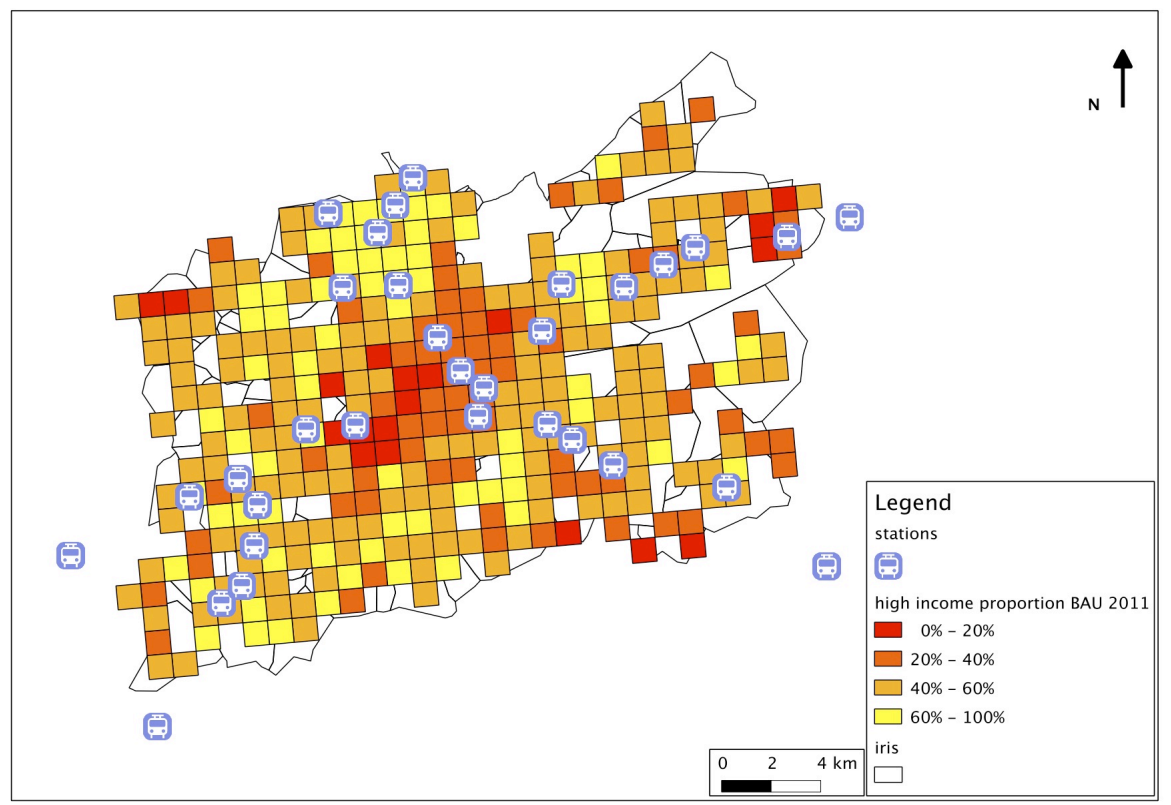

Figure 10. Proportion of high-income households in 2011. 


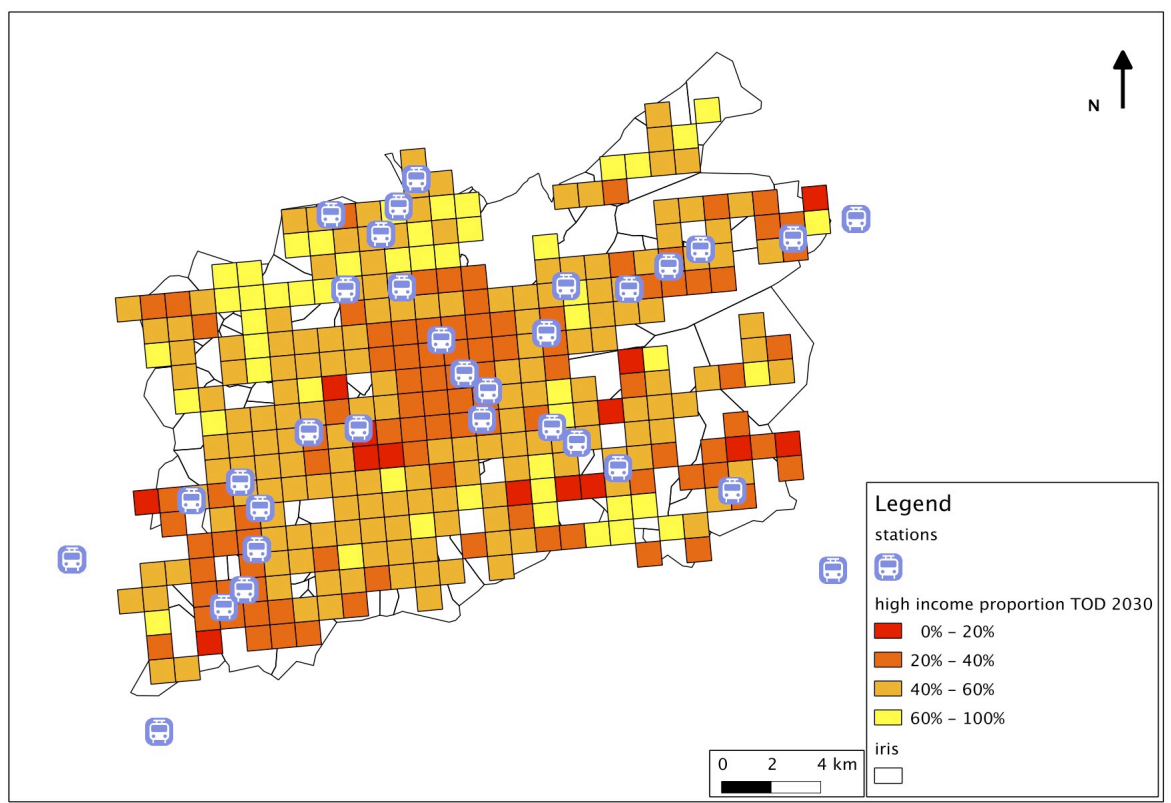

Figure 11. Proportion of high-income households in 2030 (TOD scenario).

Last, the residential choice model of Mobisim provides an evaluation of households' satisfaction very similar to a microeconomic utility. While the satisfaction of households globally remains stable, it is interesting to focus on households that settle in newly built housings (Figure 12).

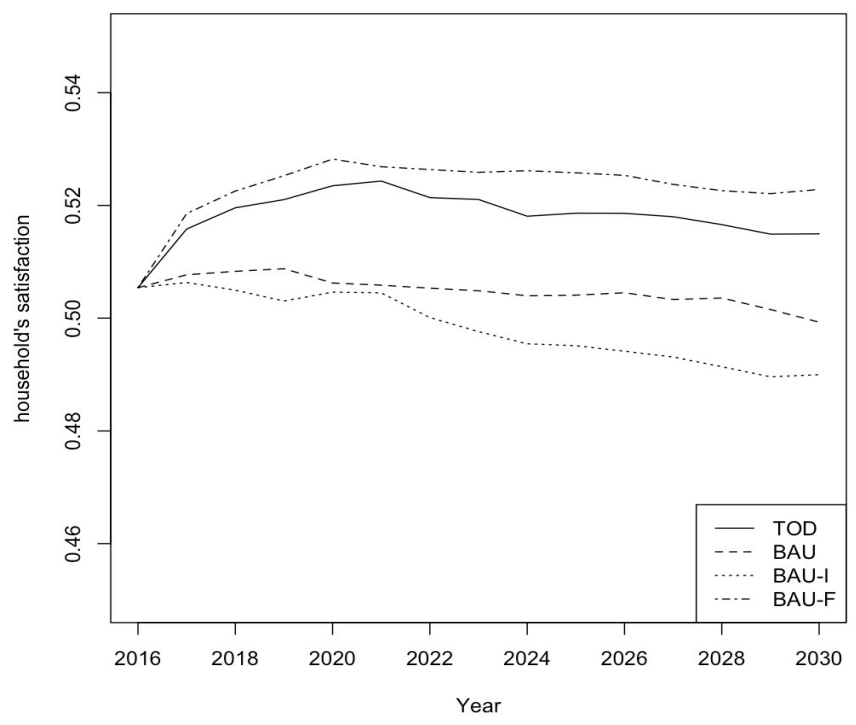

Figure 12. Evolution of households' satisfaction for inhabitants of newly built housings (normalized to the same level in 2016).

We obtain that the land use master plan designed with a multi-fractal approach (TOD and BAU-F) enables new housings to offer a better satisfaction than the unrestricted land use master plan. BAU-F even outperforms the TOD. However, the difference might be only an effect of variability in different simulation runs.

\subsection{Discussion on the results}


The four scenarios that we have designed and evaluated are contrasted enough to give us some insight of the potential of local TOD and regional TOD for a medium-sized French city such as Besançon.

Our simulations show first that even on a well-equipped territory such as Besançon, a public transportation network project has a definite effect towards sustainable urban mobility by increasing the modal share of public transport to the detriment of private cars.

However, a transport policy alone is not sufficient to foster land use pattern to evolve in a sustainable way and prevent sprawling urban forms. A holistic urban strategy, coordinating land use and transport development, is required to go towards more sustainable and effective cities.

On the contrary, the evaluation of a scenario based exclusively on a land use policy without any modification of the transit supply (BAU-F) is also partially satisfying as it allows quite good results in fighting urban sprawl and from the household satisfaction point of view, but is not effective for example in reducing car dependence.

The TOD scenario is the only one that gives positive feedback on the all aspects:

- car dependence is reduced of $1 \%$

- the use of public transport is enhanced not only in the centre but in the rural areas too,

- urban development is kept controlled preventing urban sprawl without conducting a concentrate densification of lands

- households satisfaction is increased (even if a little bit less than for the BAUF)

Therefore the TOD scenario enhances the success of integrating and harmonised land use and transport policies.

\section{Conclusion}

Why do we defend TOD as an alternative to the concentration of densities (a dense and compact city)? A multiplicity of questions is at the basis of this research. We try here to give some insights on the issues that we wanted to tackle by conducting this study.

Considering our assumption on TOD as an US-made concept, initially implemented in sprawled and big metropolises, we have shown in our research that its implementation in dense and medium French cities is effective in fighting against urban sprawl and increasing transit modal share while keeping or making people satisfied about the living environment. We can somehow say that acceptability of TOD is verified in our scenario (but we would rather not to generalise this kind of result).

We have also shown that the coordination between land-use and transport policies brings a real added value in terms of results compared to exclusive transport- or land-use policy based scenarios.

We did not focus here on comparison between the TOD strategy (distributed densification) and to the compact city scheme (concentrated densification). This will be done later in the VILMODes project [27] as a compact scenario is also tested and evaluated [28]. However, what we showed here is that, for the case of Besançon and 
taking into account all assumptions made and the limits of the modelling approach, an alternative seems possible.

However, the possible efficiency of the TOD approach (as transposed into scenarios and evaluated by our models) tells nothing of its possible implementation from decisionmakers and developers viewpoints. The French urban planning environment is equipped of effective tools (master plans and urban mobility plans) that can help them in put this kind of strategy into practice. This is why we have used these tools to specify our scenarios. However, as masters of the simulation, we have been able to perform perfect coordination of these policies. The main barrier we could maybe identify here is the multi-scales character of the approach that can lead to difficulties in terms of governance and consultation among different kind of stakeholders and of political positioning.

Finally, we didn't tackle in our scenario the behavioural dimension (paragraph 2.3), but we are strongly convinced that a substantial change in household mobility behaviour can be induced if the public transport service becomes more competitive. To improve the transit supply and promote multimodal itineraries especially in secondary centres play an essential role in affecting people modal choice for their daily trips.

\section{References}

\subsection{Journal articles}

[1] L. Bertolini, Sustainable urban mobility, an evolutionary approach, European Spatial Research and Policy Vol.12, 1, (2005) pp. 109-125

[2] Daniel G. Brown, Kenneth M. Johnson, Thomas R. Loveland, and David M. Theobald. Rural land-use trends in the conterminous united states, 1950-2000. Ecological Applications 15 (2005) pp. $1851-1863$

[3] R. Buehler, Transport Policies, Automobile Use and Sustainable Transport: A Comparison of Germany and the United States. Journal of Planning Education and Research, 30, 1 (2010) pp. 7693

[4] G. Giuliano, J. Dargay, Car ownership, travel and land use: a comparison of the US and Great Britain. Transportation Research Part A: Policy and Practice, 40, 2 (2006) pp. 106-124

[5] S. Handy, Review of the book "The Transit Metropolis: A Global Inquiry", Robert Cervero, 1998. Journal of Planning Education and Research, 19, (1999) pp. 107-109

[6] J. Holtzclaw, F. Clear, H. Dittmar, D. Goldsten and P. Haas, Location efficiency: neighborhodds and socio economic characteristics determine auto ownership and use, Transport Planning and Technology, 25, 1 (2002) pp. 1-27

[7] E. John. R. Hasse, G. Lathrop, Land resource impact indicators of urban sprawl. Applied Geography, 23 (2003) pp. 159-175

[8] K.M. Johnson, C.L. Beale, The Recent Revival of Widespread Population Growth in Nonmetropolitan Areas of the United States. Rural Sociology, 59, 4 (1994) pp 655-667

[9] D. Olaru, B. Smith, J.H.E. Taplin, Residential location and transit oriented development in a new rail corridor, Transportation Research Part A, 45 (2011) pp. 219-237

[10] J. Pucher, Urban Passenger transport in the United State and Europe a comparative analyses of public policies. Transport reviews, 15, 2 (1995) pp. 99-117 
[11] C. Tannier, G. Vuidel, P. Frankhauser, H. Houot, Simulation fractale d'urbanisation - MUPcity, un modèle multi-échelle pour localiser de nouvelles implantations résidentielles. Revue internationale de Géomatique, 20, 3 (2010) pp. 303-329

[12] P. van de Coeveringa, T. Schwanenb, Re-evaluating the impact of urban form on travel patterns in Europe and North-America. Transport Policy, 13, 3 (2006) pp. 229-239

\subsection{Book}

[13] J.P. Antoni (sous la direction de), Modeliser la Ville Formes urbaines et politiques de transport, Ed. Economica, Paris (2011)

[14] F. Ascher, Métapolis ou l'avenir des villes, Odile Jacob, Paris (1995)

[15] M. Bernick, R. Cervero, High-speed Rail and Development of California's Central Valley: Comparative Lessons and Public Policy Considerations. University of Berkeley Publication, California, (1996)

[16]R. Burgess, Compact Cities: Sustainable Urban Forms for Developing Countries E. \& F.N. Spon, (2000)

[17]E. Burton, M.Jenks,K. Williams, The compact city: a sustainable urban form? E. \& F.N. Spon (1996)

[18] P. Calthorpe, Foreword in H. Dittmar, G. Ohland, The new transit town. Best practices in transit-oriented development. Island Press Washington, California (2004)

[19] R. Cervero, The Transit Metropolis. A global inquiry. Island Press Washington - California (1998)

[20] H. Dittmar, G. Ohland, The new transit town. Best practices in transit-oriented development. Island Press Washington, California (2004)

[21] K.M. Johnson, The rural rebound, Reports on America, 1, 3 (1999)

[22] P. Newman, J. Kenworth, Sustainability and Cities: Overcoming Automobile Dependence ISLAND Press (1999)

[23] OECD, Compact city policies. A comparative Assessment. OECD Green Growth Studies, OECD publishing (2012)

[24] M. Padeiro, Le métro hors les murs : prolongements de lignes et évolution urbaine de la banlieue parisienne, thèse de doctorat de l'Université Paris Est (2009)

[25] T.L. Saaty, Compact City: The next urban evolution in response to climate change RWS Publications, Pittsburgh, PA (2013)

\subsection{Chapter in a book}

[26] Frankhauser P., Tannier, C., Vuidel G., Houot H, Une approche multi-échelle pour le développement résidentiel des nouveaux espaces urbains. Modéliser la ville. Forme urbaine et politiques de transport. Antoni J-P., (éd.). Paris : Economica (2010)

\subsection{Conference proceedings}

[27] Antoni J.P., Bonin O., Frankhauser P., Hirtzel J., Houot H., Le Nechet F., Tannier C., Tomasoni L., Ville et mobilités durable : une évaluation par la simulation (Vilmodes) - Colloque International Modélisation, Dynamique Urbaine et Étalement Urbain, 4-7 Juin 2013, Orléans (France) 
[28] Antoni J.P., Le Nechet F., Thierry C.., Compact city : agent-based model for sustainability assessment - 18th European Colloquium on Theoretical and Quantitative Geography (ECTQG), 59 Septembre 2013, Dourdan (France)

[29] Bonin O., L. Tomasoni, Rendre la ville plus compacte : réflexion autour d'un scénario alternatif à l'augmentation des densités. Proceedings of the International Conference LABEX Futurs urbains January 16-18, 2013, Champs-sur-Marne, France

[30] Bonin O., Tomasoni L., Frankhauser P., Houot H., Lunardi N., Chanard C., Building scenarios for a LUTI model: articulation of space--based models and an agent base model - 18th European Colloquium on Theoretical and Quantitative Geography (ECTQG), 5-9 Septembre 2013, Dourdan (France)

[31] R. Cervero, Transit Oriented Development in America: Strategies, Issues, Policy Directions. Proceedings of the International Conference on Transit Oriented Development - Making It Happen July 5-8, 2013, Fremantle, Western Australia

\subsection{Working papers and reports}

[32] D. Belzer and G. Autler, Transit oriented development: moving from rhetoric to reality, Discussion Paper Prepared for The Brookings Institution Center on Urban and Metropolitan Policy And The Great American Station Foundation (2002)

[33] Calthorpe Associates, Transit Oriented Development Design Guidelines for the City of San Diego. Report, City of San Diego Land guidance system (1992)

[34] P. Frankhauser, The Fractalopolis model. A sustainable approach for a central place system. HAL - Hyper Article en Ligne (2012) http://hal.archives-ouvertes.fr/

[35] N. Lunardi, Mise en place de l'intermodalité dans la plateforme de simulation MobiSim.. Report, Master Géographie, Aménagement et Environnement Spécialité Information Spatiale et Aménagement, Université de Franche-Comté (2012)

\section{Authors}

Olivier BONIN is a geographical state engineer and holds a $\mathrm{PhD}$ in Statistics. He has carried out research in the fields of mathematics, geographical information science, quantitative geography and regional science. He is currently researcher at IFSTTAR, the French institute of science and technology for transport, development and networks, and deputy director of LVMT, Laboratoire Ville Mobilité Transport, a joint research center of IFSTTAR, Ecole des Ponts, and Université Paris-Est Marne-la-Vallée.

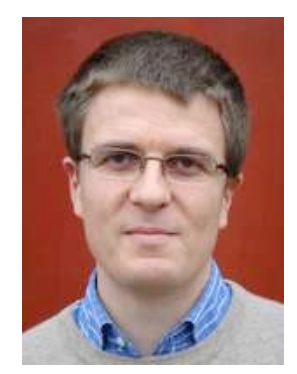

Lorenza TOMASONI is a civil engineer and doctor in urban planning at the University of Genoa (Italy) with a thesis on urban transport in southern Mediterranean developing countries. After her phd, she pursued her research in France at the LVMT, Laboratoire Ville Mobilité Transport of the Ecole des Ponts Paritech, where she spent 18 months as post-doctorate researcher in the VILMODes project. She is currently recruited as post-doc at LABEX Futurs Urbains of the University Paris-Est and Ecole des Ponts Paritech to analyze the use of urban modeling in the decision-making process, with a focus on urban

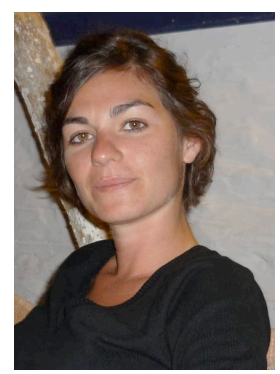


Vol. x, No. x, xxxxx, 20xx

planning practices. 